\title{
Electrooxidation of formic acid on gold: an ATR-SEIRAS study of the role of adsorbed formate
}

Angel Cuesta $^{\mathrm{a}, *}$, Gema Cabello ${ }^{\mathrm{a}}$, Fabian W. Hartl ${ }^{\mathrm{b}}$, María Escudero-Escribano ${ }^{\mathrm{a}}$, Cristina Vaz-Domínguez $^{\mathrm{a}}$, Ludwig A. Kibler ${ }^{\mathrm{b}}$, Masatoshi Osawa ${ }^{\mathrm{c}}$ and Claudio Gutiérrez ${ }^{\mathrm{a}}$

aInstituto de Química Física "Rocasolano", CSIC, C. Serrano 119, E-28006 Madrid, Spain.

${ }^{\mathrm{b}}$ Institut für Elektrochemie, Universität Ulm, D-89069, Ulm, Germany.

${ }^{c}$ Catalysis Research Center, Hokkaido University, Kita Ku, Sapporo, Hokkaido 0010021, Japan.

*Corresponding Author

E-mail address: a.cuesta@iqfr.csic.es

ABSTRACT: Formate was found to be the only adsorbed species detected with timeresolved ATR-SEIRAS during the electrooxidation of formic acid on $\mathrm{Au}$ in acidic media. No adsorbed $\mathrm{CO}$ was detected, since even in $\mathrm{CO}$-saturated acidic solutions the adsorption of $\mathrm{CO}$ on gold is negligible. The onset of formic acid electrooxidation coincides with that of formate electroadsorption, pointing to bridge-bonded adsorbed formate as the reaction intermediate. Furthermore, at constant potential the current increases quadratically with the formate coverage, which indicates that the ratedetermining step in the oxidation of adsorbed formate to $\mathrm{CO}_{2}$ is a bimolecular reaction between adjacent formate species. The rate of this reaction was unaffected by potential changes, which unequivocally confirms its chemical character.

KEYWORDS: Au; formic acid; ATR-SEIRAS; electrooxidation; direct path; adsorbed formate.

\section{Introduction}

Electrooxidation of formic acid attracts interest from both the applied and the fundamental points of view. From an applied perspective, unravelling the reaction mechanism can help to design more efficient electrocatalysts for direct formic acid fuel cells (DFAFC), that can reach high power densities [1-3] and could be power sources for portable electronic devices [4]. From a fundamental point of view, formic acid is, after carbon monoxide, the simplest possible oxygenated carbon-containing fuel, serving as a model for studies of the electrooxidation of small organic molecules. In addition, it has been shown that the electrooxidation of methanol (another attractive candidate for direct liquid fuel cells) and formaldehyde through the direct pathway (the pathway not mediated by adsorbed $\mathrm{CO}\left(\mathrm{CO}_{\mathrm{ad}}\right)$, a catalytic poison) follows a sequential mechanism, in which the oxidation to formic acid precedes the formation of $\mathrm{CO}_{2}$ [5]. It is therefore of the essence to understand the details of the mechanism of the 
electrooxidation of formic acid before attempting to unveil those of more complicated molecules, like formaldehyde or methanol.

It is widely accepted that the electrooxidation of formic acid (and of oxygenated $\mathrm{C} 1$ organic molecules in general) to $\mathrm{CO}_{2}$ follows a dual pathway mechanism [6,7], one path involving the formation of a catalytic poison (identified as $\mathrm{CO}_{\mathrm{ad}}$ in the 1980's using external-reflectance electrochemically-modulated IR spectroscopy, EMIRS [8]) and usually called the indirect path, and the other path leading to $\mathrm{CO}_{2}$ without formation of the electrocatalytic poison (direct path). Crépy et al. [9] were the first to suggest that adsorbed formate is the intermediate in the electrooxidation of formic acid on gold, which proceeds exclusively through the direct pathway, and Hahn et al. [10] were the first to attribute a band around $1320 \mathrm{~cm}^{-1}$ to adsorbed formate in an in situ externalreflectance EMIRS study of the adsorption of formic acid on a rhodium electrode. Osawa and co-workers were the first to unequivocally show, using surface-enhanced infrared absorption spectroscopy in the attenuated total reflection mode (ATRSEIRAS), the presence of bridge-bonded adsorbed formate $\left(\mathrm{HCOO}_{\mathrm{ad}}\right)$ during the oxidation of formic acid on $\mathrm{Pt}$ [11] and Pd [12] electrodes, and to suggest that it is the reactive intermediate in the direct path. Chen et al. $[13,14]$ argued later that, on the contrary, formate is a site-blocking spectator species, and that most of the oxidation current is carried by a third path involving the direct, complete electrooxidative dehydrogenation of formic acid via a weakly adsorbed molecular formic acid precursor. However, it has been very recently shown that this hypothesis contradicts the experimental results, and that formate must indeed be the reactive intermediate in the direct pathway [15]. Very recently, we have shown that formate is actually the key reaction intermediate, common to both the direct and indirect paths [16].

A major difficulty when attempting to study the mechanism of the direct pathway of formic acid electrooxidation is the interference of the $\mathrm{CO}$ pathway. This can be avoided by using $\mathrm{Pd}$ electrodes (onto which a negligible amount of $\mathrm{CO}_{\mathrm{ad}}$ is formed during $\mathrm{HCOOH}$ electrooxidation, the reaction occurring nearly exclusively through the direct pathway) instead of Pt $[12,17,18]$. However, due to the high activity of palladium, the intensity of the formate band is rather low, hindering the analysis of the dependence of the current density on the formate coverage $\left(\theta_{\text {formate }}\right)$. A promising alternative is gold, onto which $\mathrm{CO}$ is known to adsorb weakly in acidic media (and, hence, desorbs from the surface when $\mathrm{CO}$ is removed from the solution [19]), and which shows a moderate activity towards formic acid oxidation. We report here an ATR-SEIRAS study of the oxidation of formic acid on Au electrodes that provides additional strong evidence that adsorbed formate must be the active intermediate in the direct pathway. In addition, the results strongly support a mechanism in which formate electroadsorption is followed by its decomposition to $\mathrm{CO}_{2}$ in a chemical bimolecular reaction between adjacent formate species.

\section{Experimental Section}


ATR-SEIRA spectra were recorded with a Nicolet 6700 FTIR spectrometer equipped with an MCT detector, using p-polarized light. Each spectrum consisted of a single interferogram, collected with a spectral resolution of $8 \mathrm{~cm}^{-1}$ in the rapid scan mode, with a time resolution of $140 \mathrm{~ms}$. The differential spectra were calculated as $\log \left(R_{\text {sample }} / R_{\text {reference }}\right)$, where $R_{\text {reference }}$ and $R_{\text {sample }}$ are the reference and sample spectra, respectively, collected either at different potentials, or at the same potential before and after addition of formic acid, respectively.

The working electrode was a thin gold film deposited on a $\mathrm{Si}$ prism bevelled at $60^{\circ}$ following a previously reported chemical procedure [20]. The Au-covered Si prism was then attached to the spectroelectrochemical cell, using an O-ring to prevent the electrolyte from leaking. Electrical contact to the gold film was achieved by pressing against it a copper foil or a circular $\mathrm{Au}$ wire by means of an O-ring. Before the experiments the $\mathrm{Au}$ surface was electrochemically cleaned by repetitive potential cycling between 0 and $1.4 \mathrm{~V}$ vs. RHE in the supporting electrolyte (either $0.1 \mathrm{M} \mathrm{HClO}_{4}$ or $0.1 \mathrm{M} \mathrm{H}_{2} \mathrm{SO}_{4}$ ). A coiled gold wire and either a reversible hydrogen electrode (RHE) or a saturated silver/silver chloride electrode were used as counter and reference electrodes, respectively, although all the potentials in the text are referred to the RHE scale.

The working solutions were prepared either from concentrated $\mathrm{H}_{2} \mathrm{SO}_{4}$ (Merck Suprapure) or $\mathrm{HClO}_{4}$ (Merck, p.a.), 88-91\% HCOOH (Fluka puriss. p.a.), and Milli-Q water. The solutions were deaerated with Nitrogen (N50, Air Liquide) before the experiments.

\section{Results}

The electrooxidation of formic acid on gold was first studied by applying a potential step from $0.1 \mathrm{~V}$, a potential at which no oxidation current can be measured and at which no adsorbates can be detected on the electrode surface, to a more positive potential. During the potential step time-resolved spectra and the current transient were simultaneously recorded. A typical experiment, corresponding to a potential step to 0.9 $\mathrm{V}$ in $0.1 \mathrm{M} \mathrm{HClO}_{4}+0.05 \mathrm{M} \mathrm{HCOOH}$, is shown in Fig. 1. The $\mathrm{S} / \mathrm{N}$ ratio of the spectra is comparable to that in previous ATR-SEIRAS work by us and by others (please note that the absorption coefficient of the symmetric mode of formate is much smaller than that of $\mathrm{CO}$ ), but, due to the large number of spectra in Figure 1A, and to the increase of the baseline as a consequence of the potential step, the features of every individual spectrum are not easily discernible. For this reason, and for the sake of clarity, we have extracted one of the spectra recorded at $0.9 \mathrm{~V}$ (Fig. 1B), and a plot of the integrated intensity of the band at $1330 \mathrm{~cm}^{-1}$ (corresponding to the symmetric stretching of adsorbed formate) as a function of time during the potential step experiment is shown in Fig. 1C.

As expected from the fact that $\mathrm{CO}$ does not adsorb on gold in $\mathrm{CO}$-free acidic solutions, only $\mathrm{HCOO}_{\mathrm{ad}}$, whose symmetric stretching appears at $1327 \mathrm{~cm}^{-1}$, is detected on the 
electrode surface. The two negative absorption bands around 3300 and $1650 \mathrm{~cm}^{-1}$ correspond to the $\mathrm{OH}$ stretching and $\mathrm{HOH}$ bending modes of water, respectively, and appear as a consequence of the displacement of interfacial water by $\mathrm{HCOO}_{\mathrm{ad}}$ and of the changes in the structure of the interfacial water layer provoked by the potential step [21]. The absence of bands corresponding to adsorbed carbon monoxide in Fig. 1 clearly shows that the oxidation of formic acid to $\mathrm{CO}_{2}$ proceeds exclusively through the direct pathway.

The immediate formation of $\mathrm{HCOO}_{\mathrm{ad}}$ upon stepping the potential to the region where oxidation of $\mathrm{HCOOH}$ occurs, as illustrated in Fig. 1, already suggests that adsorbed formate is the reactive intermediate of the reaction. This becomes more evident when both the current (sampled at $0.5 \mathrm{~s}$ after the potential step to avoid the contributions of double-layer charging) and the integrated intensity of the formate band $\left(I_{\mathrm{HCOO}}\right)$ are plotted as a function of potential (Fig. 2). It is clear that the emergence of the band corresponding to $\mathrm{HCOO}_{\mathrm{ad}}$ in the ATR-SEIRA spectra and the onset of $\mathrm{HCOOH}$ oxidation are concomitant. Moreover, the positive shift by $0.15 \mathrm{~V}$ of the potential at which $\mathrm{HCOO}_{\mathrm{ad}}$ is first observed in sulphuric acid as compared to perchloric acid solutions is mirrored by an identical shift in the onset of $\mathrm{HCOOH}$ oxidation. Furthermore, the lower $I_{\mathrm{HCOO}}$ values in sulphuric acid solutions are accompanied by lower currents for the oxidation of $\mathrm{HCOOH}$. The same correlation between formate coverage and oxidation current has been reported previously in a combined electrochemical and SERS study of formic acid electrooxidation on Au [22]. All these results, similar to those previously reported for Pt [15], clearly show that $\mathrm{HCOO}_{\mathrm{ad}}$ must be the reactive intermediate in the direct pathway (the only active one on $\mathrm{Au}$ ) of formic acid electrooxidation. It is also evident from plots of $I_{\mathrm{HCOO}}$ vs. the concentration of $\mathrm{HCOOH}\left(c_{\mathrm{HCOOH}}\right)$ at constant potential (Fig. S1) that, under the same experimental conditions, $\theta_{\text {formate }}$ (the formate coverage per surface Au atom) is always higher in perchloric than in sulphuric acid solutions, this being a clear indication that sulphate (a specifically adsorbing anion) and formate compete for the adsorption sites on the gold surface. At positive enough potentials, sulfate adopts on $\mathrm{Au}(111)$ electrodes a $\sqrt{3} \times \sqrt{7}$ structure with a coverage of $0.22 \mathrm{ML}$ [23], that completely covers the surface. On $\mathrm{Au}(100)$, an ordered structure with a similar coverage is formed at much more negative potentials [24,25]. Similar coverages can be expected for (110) sites or at defects at even more negative potentials. The effect of sulfate on the oxidation of formic acid is similar in the case of Pt [15].

A problem with potential step experiments performed at different $c_{\mathrm{HCOOH}}$ is that many different solutions must be used at each potential in order to obtain a significant number of points in $i$ vs. $I_{\mathrm{HCOO}}$ and $I_{\mathrm{HCOO}}$ vs. $c_{\mathrm{HCOOH}}$ plots. This limitation can be eliminated by adding, at the desired potential, and just after starting the collection of a spectral series, the amount of concentrated $\mathrm{HCOOH}$ necessary for reaching the desired final $c_{\mathrm{HCOOH}}$ (Figure 3). Under these conditions, $c_{\mathrm{HCOOH}}$ at the interface, and therefore $\theta_{\text {formate }}$ and the oxidation current, increase slowly enough as to allow the simultaneous collection of 
time-resolved ATR-SEIRAS and the corresponding current transient. Fig. 3A shows a series of time-resolved ATR-SEIRA spectra recorded at $0.76 \mathrm{~V}$ following this procedure with an interval of $140 \mathrm{~ms}$. At the point indicated by the arrow, the volume of concentrated $\mathrm{HCOOH}$ necessary to reach a final $c_{\mathrm{HCOOH}}=0.1 \mathrm{M}$ was added to the solution. Only the first $4 \mathrm{~s}$ after the addition of formic acid are shown for clarity. Only two bands at 1720 and $1329 \mathrm{~cm}^{-1}$, corresponding to $\mathrm{HCOOH}$ in the interfacial region and to $\mathrm{HCOO}_{\mathrm{ad}}$, respectively, emerge in the spectra after addition of $\mathrm{HCOOH}$. A similar experiment at $0.96 \mathrm{~V}$ is shown in Fig. S2.

Fig. 3B shows the current transient recorded during the experiment and the time evolution of the integrated intensity of the formic acid band $\left(I_{\mathrm{HCOOH}}\right)$ and of $I_{\mathrm{HCOO}}$. (For a similar plot at $0.96 \mathrm{~V}$ see Fig. S2.) It can be clearly observed that, as $\mathrm{HCOOH}$ reaches the interface, the oxidation current, $I_{\mathrm{HCOOH}}$ and $I_{\mathrm{HCOO}}$ increase rapidly and simultaneously to a maximum, after which they all slowly decrease. The decrease is much slower in the case of $I_{\mathrm{HCOO}}$, which points to a higher than linear, e.g. quadratic, dependence of the current on $\theta_{\text {formate }}$. A similar decrease of the oxidation current is observed in potential-step experiments (see Fig. 1D) and has also been reported in similar potential-step experiments with Pt electrodes [13-15]. The parallel decrease of the oxidation current and of $c_{\mathrm{HCOOH}}$ (obviously $c_{\mathrm{HCOOH}}$ is proportional to $I_{\mathrm{HCOOH}}$ ) evidenced in Fig. 3B clearly show that the current decrease is due to transport limitations, as suggested by Osawa et al. [15].

3.1. Formate Electroadsorption. Crépy et al. [9] have proposed that the reversible electroadsorption equilibrium between $\mathrm{HCOOH}$ in solution and $\mathrm{HCOO}_{\mathrm{ad}}$ :

$$
\mathrm{HCOOH}+2 * \underset{k_{-1}}{\stackrel{k_{1}}{\rightleftharpoons}} \mathrm{HCOO}_{\mathrm{ad}}+\mathrm{H}^{+}+e
$$

(Reaction 1)

is the first step in the electrooxidation of $\mathrm{HCOOH}$ on gold in acidic media. (* denotes a free surface atom. Please note that for $\mathrm{HCOO}_{\mathrm{ad}}$ an adsorption site is composed of two surface atoms.) Langmuir plots in $0.1 \mathrm{M} \mathrm{HClO}_{4}$ (Fig. 4) of the form $1 / I_{\mathrm{HCOO}}$ vs. $1 / I_{\mathrm{HCOOH}}\left(\theta_{\text {formate }}\right.$ can be assumed to be proportional to $I_{\mathrm{HCOO}}$, an assumption applicable if the orientation of the adsorbate does not change with coverage [26,27], and if the adsorbate-adsorbate interaction is weak except at very high coverage [28]) obtained from the data in Figs. 3 and S2 show a good linear relationship, suggesting that the adsorption of formate can be described by the (completely reversible) Langmuir electroadsorption isotherm. However, in the case of a Langmuir adsorption equilibrium, a decrease of the slope of the Langmuir plot by a factor of 2154 would be expected when the potential increases by $200 \mathrm{mV}(60 \mathrm{mV}$ per decade, see the Supplementary Information), while a decrease by a factor of only 1.3 is observed (Fig. 4). The small decrease in the slope of the Langmuir plots with increasing potential (or, equivalently, the necessity of more than $800 \mathrm{mV}$ to reach the saturation coverage) might suggest that the electroadsorption of formate on Au follows a Frumkin isotherm with a large repulsive parameter, a possibility that is discussed in the article by Kibler et al. 
following this one [29]. It must be noted, however, that a Frumkin isotherm cannot explain the experimentally found linear relationship between $1 / I_{\mathrm{HCOO}}$ and $1 / I_{\mathrm{HCOOH}}$ (Fig. 4), unless we assume that the plot in Fig. 4 corresponds to the low-coverage limit, under which conditions the Langmuir and the Frumkin isotherms are undistinguishable. The small decrease of the slope of the $1 / I_{\mathrm{HCOO}}$ vs. $1 / I_{\mathrm{HCOOH}}$ plot when the potential increases by $200 \mathrm{mV}$ can be accounted for if the adsorption of formate is assumed to be completely irreversible, i.e., if adsorbed formate never desorbs as formic acid, but is further oxidized. In the steady state, adsorbed formate is oxidized at the same rate at which it is adsorbed, so that its coverage remains constant, and its concentration dependence can be formally described by a Langmuir-like isotherm. The pseudoLangmuir constant of this steady state will be the ratio between the rate constant of formate adsorption and the rate constant of formate oxidation, while the Langmuir constant of a reversible equilibrium is the ratio between the rate constants of adsorption of a species and of desorption of exactly the same species. Therefore, $\mathrm{HCOO}_{\mathrm{ad}}$ must undergo a decomposition reaction, and, since the only reaction taking place is the electrooxidation of $\mathrm{HCOOH}$ to $\mathrm{CO}_{2}$, this is a solid proof that adsorbed formate is the reactive intermediate.

Since the decomposition of $\mathrm{HCOO}_{\mathrm{ad}}$ follows a quadratic law (see below), the Langmuirlike dependence of $\theta_{\text {formate }}$ on $c_{\mathrm{HCOOH}}$ can only be possible if two formic acid molecules adsorb together and simultaneously on two adjacent adsorption sites (although each adsorption site is composed of two Au atoms, in the classical Langmuir formalism they are considered as a single site). This requirement may appear strange, but it is well known that carboxylic acids have a strong tendency to form cyclic and/or linear dimers, held together by hydrogen bonds, even in aqueous solutions. In the case of $1 \mathrm{M}$ formic acid solutions, the fraction of dimers is between ca. 1 and ca. 5\% [30]. Even if the dimer population is low, exclusive or preferential adsorption from the dimer could occur if it is kinetically favored:

$$
\begin{gathered}
2 \mathrm{HCOOH} \rightleftharpoons[\mathrm{HCOOH}]_{2}+4 * \longrightarrow 2 \mathrm{HCOO}_{\mathrm{ad}}+2 \mathrm{H}^{+}+2 e \\
k_{1} K_{\mathrm{dim}} c_{\mathrm{HCOOH}}^{2}\left(\theta_{\mathrm{fomate}}^{\max }-\theta_{\mathrm{formate}}\right)^{2} \exp \left(\frac{2 \beta \Delta \phi F}{R T}\right)=k_{2} \theta_{\mathrm{fomate}}^{2}
\end{gathered}
$$

where $k_{1}$ is the rate constant of the irreversible adsorption, $K_{\operatorname{dim}}$ is the equilibrium constant for formic-acid dimerization, $\theta_{\mathrm{fomate}}^{\max }$ is the saturation formate coverage, $\beta$ is the anodic symmetry factor, $\Delta \phi$ is the potential drop across the interface and $k_{2}$ is the rate constant of the subsequent, purely chemical, same-species bimolecular decomposition reaction between adjacent formates (see below). The factor 2 in the exponential results from the necessity to transfer 2 electrons for the adsorption of two formates from one formic-acid dimer, and obviously implies that these two electrons are transferred simultaneously. Reordering: 


$$
\frac{1}{\theta_{\text {formate }}}=\frac{1}{\theta_{\text {formate }}^{\max }}+\frac{1}{\theta_{\text {formate }}^{\max } \sqrt{\frac{k_{1}}{k_{2}} K_{\mathrm{dim}}} \exp \left(\frac{\beta \Delta \phi F}{R T}\right) c_{\mathrm{HCOOH}}}
$$

For an irreversible bimolecular Langmuir-like electroadsorption, and if the symmetry factor for the electroadsorption of formate $(\beta)$ has the typical value of 0.5 , a decrease of the slope in a Langmuir plot by a factor of 46.4 would be expected for an increase of the potential of $200 \mathrm{mV}$ (120 mV per decade), still clearly larger than the experimentally observed value, this being an indication that $\beta<0.5$ (see the Supplementary Information).

3.2. Decomposition of Adsorbed Formate. If $\mathrm{HCOO}_{\mathrm{ad}}$ is the reactive intermediate, the oxidation current at constant potential and varying $\mathrm{HCOOH}$ concentration must increase with $\theta_{\text {formate }}$. This is indeed the case, and actually the dependence is quadratic, as can be seen in Fig. 5A, where the oxidation current recorded during the experiment in Fig. 3 has been plotted against the square of $I_{\mathrm{HCOO}}$ obtained in the same experiment. A plot with the data obtained at $0.96 \mathrm{~V}$ has also been included. The same quadratic dependence was obtained from potential step experiments at different $c_{\mathrm{HCOOH}}$ (Fig. S3), both in perchloric and in sulphuric acid solutions. The higher slope in the first case indicates that the adsorption of sulphate decreases the reaction rate by decreasing the number of available adsorption sites, and therefore $\theta_{\text {formate, }}$ but does not affect the reaction mechanism. Figs. 5 and S3 unequivocally confirm the quadratic increase of the oxidation current with $\theta_{\text {formate }}$. In addition, they show that, within experimental error, the same current vs. $\theta_{\text {formate }}$ dependence is obtained at different potentials. Therefore, the rate at which $\mathrm{HCOO}_{\mathrm{ad}}$ is oxidized to $\mathrm{CO}_{2}$ depends exclusively on $\theta_{\text {formate }}$ increasing the potential simply decreases the concentration at which a given coverage is achieved, as expected from Reaction 1 and observed in Fig. S1. Hence

$$
i=k_{2} \theta_{\text {formate }}^{2}
$$

This is a very important result, because it unequivocally means that the rate-determining step (rds) in the oxidation of $\mathrm{HCOO}_{\mathrm{ad}}$ to $\mathrm{CO}_{2}$ is a purely chemical, same-species bimolecular reaction between adjacent formates, and that this chemical step is necessarily intercalated between the first and second electron transfers.

Tafel plots of the oxidation of formic acid in $0.1 \mathrm{M} \mathrm{HClO}_{4}$ yield, in the range between 0.4 and $0.8 \mathrm{~V}$, slopes between 240 and $270 \mathrm{mV}$, in excellent agreement with the values of approximately $240 \mathrm{mV}$ obtained by Crépy et al. [9] and by Beltramo et al. [22]. These high values of the Tafel slope are another clear indication that the adsorption of formate is irreversible, because for a reversible electroadsorption followed by a chemical step the Tafel slope would never be higher than $60 \mathrm{mV}$ (see the Supplementary Information). Please note that, at the low coverage limit, a mechanism composed of a reversible electroadsorption followed by a chemical step has a Tafel slope of $60 \mathrm{mV}$ both for Langmuir and for Frumkin adsorption. In both cases, as the 
coverage increases, the Tafel slope will increase (strictly speaking, the term Tafel slope is no longer valid beyond the low coverage limit, because a plot of $E$ vs. $\log i$ will no longer be linear), and will be infinite when the saturation coverage is reached. The only difference between Langmuir and Frumkin adsorption will be that the increase of the Tafel slope will be faster in the latter case. On the contrary, for an irreversible adsorption followed by a chemical step, the Tafel slope will be $2.3(R T / 2 \beta F)$ if two formates adsorb simultaneously on two adjacent adsorption sites from a formic-acid dimer (see the Supplementary Information), as suggested by the results in Fig. 4. For the typically assumed value of $\beta=0.5$ this corresponds to $60 \mathrm{mV}$, clearly below the experimental value. The Tafel slope between 240 and $270 \mathrm{mV}$ suggests that $\beta$ is between 0.125 and 0.11 , in good agreement with the conclusion that $\beta<0.5$ obtained from the Langmuir plots in Fig. 4. A small value of $\beta$ implies that the transition state of formate electroadsorption resembles more the initial reactant $\left([\mathrm{HCOOH}]_{2}\right)$ than its oxidation product $\left(\mathrm{HCOO}_{\mathrm{ad}}\right)$, or, equivalently, that the electron transfer occurs closer to the outer Helmholtz plane (OHP) than to the electrode surface.

The mechanism proposed here for the electrooxidation of formic acid on gold is qualitatively similar to that proposed by Beltramo et al. [22], who also reached the conclusion that $\mathrm{HCOO}_{\mathrm{ad}}$ must be the intermediate in the reaction mechanism. In both our mechanism and in that of reference [22], formate electroadsorption is the first step of the reaction (and the increase of $\theta_{\text {formate }}$ with increasing potential obviously controls the Tafel slope of the reaction), which is followed by the decomposition of $\mathrm{HCOO}_{\mathrm{ad}}$. But, while Beltramo et al. assumed that formate electroadsorption is in equilibrium, we show here that it must not necessarily be so. Furthermore, Beltramo et al. did not obtain a quantitative relationship between $\theta_{\text {formate }}$ and the reaction rate, and assumed that the second step is the electrooxidation of one $\mathrm{HCOO}_{\mathrm{ad}}$ to $\mathrm{CO}_{2}$, while we demonstrate here that it must correspond to the purely chemical bimolecular decomposition of two adjacent $\mathrm{HCOO}_{\mathrm{ad}}$, that precedes the second electron transfer. As shown below, our mechanism describes quantitatively all the experimental observations, including the high Tafel slope at the onset of the oxidation (i.e., at low $\theta_{\text {formate }}$ ).

\subsection{Reaction Kinetics. From Eqs. 1 and 3 it is evident that:}

$$
i=\frac{\left(\theta_{\mathrm{formate}}^{\max }\right)^{2} k_{1} K_{\mathrm{dim}} \exp \left(\frac{2 \beta \Delta \phi F}{R T}\right) c_{\mathrm{HCOOH}}^{2}}{\left(1+\sqrt{\frac{k_{1}}{k_{2}} K_{\mathrm{dim}}} \exp \left(\frac{\beta \Delta \phi F}{R T}\right) c_{\mathrm{HCOOH}}\right)^{2}}
$$

Which upon reordering yields:

$$
\frac{1}{i^{1 / 2}}=\frac{1}{\theta_{\mathrm{fom} m a t e}^{\max } k_{2}^{1 / 2}}+\frac{1}{\theta_{\mathrm{fomate}}^{\max } \sqrt{k_{1} K_{\mathrm{dim}}} \exp \left(\frac{\beta \Delta \phi F}{R T}\right) c_{\text {HсоOH }}}
$$


Accordingly, a plot of $1 / i^{1 / 2}$ vs. $1 / I_{\mathrm{HCOOH}}$ must be linear, with an ordinate at the origin of $1 / \theta_{\mathrm{fom} m a t e}^{\max } k_{2}^{1 / 2}$ (Fig. 5B). The same value of $\theta_{\mathrm{fom} m a t e}^{\max } k_{2}^{1 / 2}$ is obtained both at 0.76 and at $0.96 \mathrm{~V}$, confirming that the rds in the oxidation of $\mathrm{HCOO}_{\mathrm{ad}}$ to $\mathrm{CO}_{2}$ must be chemical. The slope at $0.76 \mathrm{~V}$ is only 1.7 times higher than that at $0.96 \mathrm{~V}$, this difference being much smaller than that expected from the exponential dependence of the second term in Eq. (5) if $\beta=$ 0.5. If, instead, $0.11<\beta<0.125$, as deduced from the analysis of the Tafel slope (see above), a decrease in the slope by a factor of 2.3-2.6 should be obtained for an increase in the potential of $200 \mathrm{mV}$, in reasonable agreement with the observed decrease by a factor of 1.7 .

\section{Discussion}

The simplest mechanism compatible with all of the above results is:

$$
\begin{aligned}
& 2 \mathrm{HCOOH} \rightleftharpoons[\mathrm{HCOOH}]_{2}+4 * \longrightarrow 2 \mathrm{HCOO}_{\mathrm{ad}}+2 \mathrm{H}^{+}+2 e \\
& 2 \mathrm{HCOO}_{\mathrm{ad}} \longrightarrow 2 \mathrm{CO}_{2}+\mathrm{H}_{2}+4^{*} \\
& \mathrm{H}_{2} \longrightarrow 2 \mathrm{H}^{+}+2 e
\end{aligned}
$$

(Reaction 2)

(Reaction 3)

(Reaction 4)

The formation of $\mathrm{H}_{\mathrm{ad}}$ in the second step is unlikely, since the $\mathrm{H}$ atom in $\mathrm{HCOO}_{\mathrm{ad}}$ is rather removed from the electrode surface, and, although Au shows little activity for $\mathrm{H}_{2}$ electrooxidation, the last step should proceed readily, given the huge overpotential. The proposed rupture of the $\mathrm{C}-\mathrm{H}$ bond in the second step is in agreement with the high kinetic isotope effect found by Chen et al. $[13,31]$ for the oxidation of $\mathrm{HCOOH}$ on $\mathrm{Pt}$ electrodes.

The reported observation that, contrarily to the formation of $\mathrm{CO}_{\mathrm{ad}}$, no sites in addition to those already occupied by $\mathrm{HCOO}_{a d}$ are required for its oxidation to $\mathrm{CO}_{2}$ [32] suggests that both $\mathrm{HCOO}_{\mathrm{ad}}$ remain upright in the transition state. We suggest that for the reaction to occur the two $\mathrm{HCOO}_{\mathrm{ad}}$ must lean towards each other, until their $\mathrm{H}$ atoms are so near that the simultaneous rupture of the two $\mathrm{C}-\mathrm{H}$ bonds and the formation of the $\mathrm{H}-\mathrm{H}$ bond ensue. It is a well-known fact that, at the metal-gas interface, $\mathrm{HCOOH}$ adsorbs as $\mathrm{HCOO}_{\mathrm{ad}}$ on most metal surfaces [33-38], and that $\mathrm{HCOO}_{\mathrm{ad}}$ decomposes then to $\mathrm{CO}$ and $\mathrm{H}_{2} \mathrm{O}$ and/or to $\mathrm{CO}_{2}$ and $\mathrm{H}_{2}$ [33-39]. Several mechanisms have been proposed for the dehydrogenation reaction, some involving a reaction between adsorbed formate and adsorbed hydrogen [33], some others involving a bimolecular reaction between two contiguous adsorbed formates [33,39]. Amongst the latter, a mechanism involving a transition state containing two "activated" $\mathrm{H}$ atoms has been proposed [39].

The mechanism proposed here accounts for: i) the finding that the decrease of the oxidation current due to mass transport limitations observed in Fig. 3B is accompanied by a much smaller decrease in $I_{\mathrm{HCOO}}$, which points to a power-law dependence of the current on the formate coverage; ii) in agreement with the former, the quadratic dependence of the reaction rate on $\theta_{\text {formate }}$ at constant potential; iii) the finding that, 
since the quadratic dependence is unaffected by potential changes, the rds in the decomposition of $\mathrm{HCOO}_{\mathrm{ad}}$ must be chemical and be intercalated between the first and second electron transfers; this should also hold for Pt, for which a high kinetic isotope effect indicates that the rds in the decomposition of $\mathrm{HCOO}_{\mathrm{ad}}$ involves the rupture of the $\mathrm{C}-\mathrm{H}$ bond [13,31]; iv) the experimentally observed Tafel slope of $240 \mathrm{mV}$ and the experimentally observed decrease of the slope in Langmuir plots and in plots of Eq. (5) by a factor of only 2 for a potential increase of $200 \mathrm{mV}$, that can only be accounted for if the first step is an irreversible bimolecular electroadsorption with $\beta$ around 0.12 and the second step is a chemical reaction.

The role of $\mathrm{HCOO}_{\mathrm{ad}}$ as the reactive intermediate in the direct path of $\mathrm{HCOOH}$ electrooxidation also allows to explain the higher activity for $\mathrm{HCOOH}$ electrooxidation of $\mathrm{Pt}$ as compared with $\mathrm{Au}$, even though no poisoning $\mathrm{CO}_{\mathrm{ad}}$ is formed on $\mathrm{Au}$, as being due to the higher affinity of $\mathrm{Pt}$ for $\mathrm{HCOO}_{\mathrm{ad}}$. In the case of polycrystalline Pt thin-film electrodes, the onset of both $\mathrm{HCOOH}$ electrooxidation and of $\mathrm{HCOO}_{\mathrm{ad}}$ formation occurs around $0.30 \mathrm{~V}$ [15], coinciding with the potential of zero total charge (pztc) of polycrystalline Pt [40], while in the case of Au thin-film electrodes, this onset occurs at a higher potential, $0.5 \mathrm{~V}$ (Fig. 2). The lower affinity of $\mathrm{Au}$ for $\mathrm{HCOO}_{\mathrm{ad}}$ is also reflected in the fact that the inhibition of both the oxidation current and $\theta_{\text {formate }}$ by sulphate are much larger in the case of $\mathrm{Au}$ than in the case of Pt (compare Fig. 2 and Fig. S4 in ref. [15]).

Although the quadratic dependence of the current with respect to $\theta_{\text {formate }}$ at constant potential reported above is observed over the whole potential range (0.5-1.2 V) in which oxidation of $\mathrm{HCOOH}$ occurs, and although $\theta_{\text {formate }}$ continues increasing with potential up to $1.3 \mathrm{~V}$ (Fig. 6 and Fig. 2, red line), in a positive potential scan there appears a current maximum around $1.0 \mathrm{~V}$ (Fig. 6 and Fig. 2, black line. The peak at ca. $1.5 \mathrm{~V}$ corresponds to the oxidation of gold). Similarly, in the case of Pt electrodes Samjeské et al. [41-43] also found that at potentials beyond the current maximum $\theta_{\text {formate }}$ continues increasing, which led them to suggest that the oxidation of adsorbed formate to $\mathrm{CO}_{2}$ requires an adjacent free site:

$$
\mathrm{HCOO}_{\mathrm{ad}}+* \longrightarrow \mathrm{CO}_{2}+\mathrm{H}^{+}+3^{*}+e
$$

(Reaction 5)

the corresponding rate equation being:

$$
i \propto k_{2} \theta_{\text {formate }}\left(1-2 \theta_{\text {formate }}-\theta_{\text {CO }}-\theta_{\text {anions }}\right)
$$

Eq. 6 predicts a bell-shaped dependence of the reaction rate on $\theta_{\text {formate }}$ which is in agreement with the experimental current profile in a positive potential scan, but not with the quadratic dependence of the current on $\theta_{\text {formate }}$ found when the potential is kept constant and $c_{\mathrm{HCOOH}}$ is increased (see Fig. 5 and the inset in Fig. 2 in ref. [15]). This suggests that, above ca. $1.0 \mathrm{~V}$, adsorption of a blocking species occurs. Comparison of the current-potential plot (Fig. 6, black line) with the corresponding $\theta_{\text {formate }}^{2}$-potential 
curve (Fig. 6, red line) provides support for this hypothesis: at $E<1.0 \mathrm{~V}$ both plots run in parallel, in agreement with the observed quadratic dependence between $i$ and $\theta_{\text {formate }}$ reported above, but they diverge above $1.0 \mathrm{~V}$, where a shoulder can be observed in the

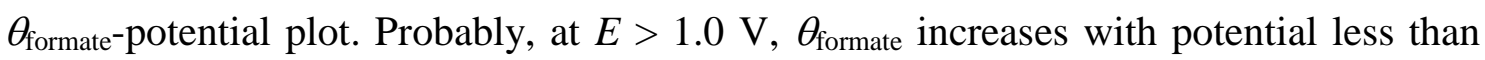
expected due to the coadsorption of a blocking species (most likely adsorbed $\mathrm{OH}$, $\mathrm{OH}_{\mathrm{ad}}$ ). The fact that in $0.1 \mathrm{M} \mathrm{H}_{2} \mathrm{SO}_{4}$, where $\mathrm{OH}$ adsorption is inhibited by the presence of adsorbed sulphate, the maximum in the current-potential plot appears at higher potentials, $E>1.2 \mathrm{~V}$ (Fig. 2B), provides further support for this hypothesis.

Therefore, in order to describe the dependence of the reaction rate on the electrode potential, the effect of blocking (like $\mathrm{OH}_{\mathrm{ad}}$ ) or poisoning (like $\mathrm{CO}_{\mathrm{ad}}$ ) species must be included in the bimolecular rate equation:

$$
i=k_{2} \theta_{\text {formate }}^{2}\left(1-\theta_{\mathrm{s}, \mathrm{p}}\right)^{n}
$$

Where $i, \theta_{\text {formate }}$ and $\theta_{\mathrm{s}, \mathrm{p}}$ (the coverage by spectator or poisoning species) are all potential-dependent. At potentials at which $\theta_{\mathrm{s}, \mathrm{p}}$ is negligible (below $1.0 \mathrm{~V}$ in the case of $\mathrm{Au}$ ), or if the experiment is performed at constant potential and increasing $c_{\mathrm{HCOOH}}$, Eq. (8) will reduce to Eq. (3).

Taking into account the results discussed above, and assuming that the spectator species is $\mathrm{OH}_{\mathrm{ad}}$, that its adsorption is at reversible equilibrium, and that it can be described by a Langmuir isotherm, the potential dependence of the oxidation current will be described by:

$$
i=\frac{\left(\theta_{\text {formate }}^{\max }\right)^{2} k_{1} c_{\text {нсоо }}^{2} \exp \left(\frac{2 \beta \Delta \phi F}{R T}\right)}{\left(1+\sqrt{\frac{k_{1}}{k_{2}}} c_{\text {НСООН }} \exp \left(\frac{\beta \Delta \phi F}{R T}\right)\right)^{2}}\left(1-\frac{\theta_{\text {ОН }}^{\max } \frac{k_{1}^{\prime}}{k_{-1}^{\prime}} c_{\mathrm{H}_{2} \mathrm{O}} \exp \left(\frac{\Delta \phi F}{R T}\right)}{1+\frac{k_{1}^{\prime}}{k_{-1}^{\prime}} c_{\mathrm{H}_{2} \mathrm{O}} \exp \left(\frac{\Delta \phi F}{R T}\right)}\right)^{n}
$$

Where $\theta_{\mathrm{OH}}^{\max }$ is the saturation $\mathrm{OH}$ coverage, ${ }^{c_{\mathrm{H}_{2} \mathrm{O}}}$ is the concentration of water, and $k_{1}{ }^{\prime}$ and $k_{-1}{ }^{\prime}$ are the $\mathrm{OH}$ adsorption and desorption rate constants, respectively. As can be seen in Fig. 6, this model fits the experimental results accurately.

\section{Conclusion}

The demonstration that bridge-bonded adsorbed formate is the reactive intermediate in the oxidation of formic acid on metal electrodes may have important consequences for the design of more efficient catalysts for DFAFCs, since it implies that the optimum material should have a high tendency to adsorb formate, and that the presence of specifically adsorbing anions must be avoided. Moreover, the results presented here unequivocally show that the second step is a purely chemical same-species bimolecular reaction between adjacent formates, whose rate is unaffected by the potential and that must precede the second electron transfer. This step involves the rupture of the $\mathrm{C}-\mathrm{H}$ bond, in agreement with the finding for Pt of a high kinetic isotope effect [13,31]. 


\section{ACKNOWLEDGMENT}

Funding from the DGI (Spanish Ministry of Education and Science) through Projects CTQ2009-07017 and PLE2009-0008 is gratefully acknowledged. M.E.-E. acknowledges an FPI fellowship from the Spanish Ministry of Science and Innovation and an accommodation grant at the Residencia de Estudiantes from the Madrid City Council. C. V.-D. acknowledges a JAE-Doc fellowship from CSIC.

\section{APPENDIX A. Supplementary Data}

Supplementary data associated with this article can be found, in the online version, at doi:10.1016/j.cattod.2012.xx.xxx.

\section{References}

[1] S. Ha, R. Larsen, R.I. Masel, J. Power Sources 144 (2005) 28.

[2] Y. Zhu, Z. Khan, R.I. Masel, J. Power Sources 139 (2005) 15.

[3] R. Larsen, S. Ha, J. Zakzeski, R.I. Masel, J. Power Sources 157 (2006) 78.

[4] C. Rice, S. Ha, R.I. Masel, P. Waszczuk, A. Wieckowski, T. Barnard, J. Power Sources 111 (2002) 83.

[5] S. Lai, N. Lebedeva, T. Housmans, M. Koper, Top. Catal. 46 (2007) 320.

[6] M. Breiter, Electrochemical Processes in Fuel Cells, ed., Springer Verlag, Berlin, 1969.

[7] R. Parsons, T. Van der Noot, J. Electroanal. Chem. 257 (1988) 9.

[8] B. Beden, A. Bewick, C. Lamy, J. Electroanal. Chem. 148 (1983) 147.

[9] G. Crépy, C. Lamy, S. Maximovitch, J. Electroanal. Chem. 54 (1974) 161.

[10] F. Hahn, B. Beden, C. Lamy, J. Electroanal. Chem. 204 (1986) 315.

[11] A. Miki, S. Ye, M. Osawa, Chem. Commun. (2002) 1500.

[12] H. Miyake, T. Okada, G. Samjeske, M. Osawa, Phys. Chem. Chem. Phys. 10 (2008) 3662.

[13] Y.X. Chen, M. Heinen, Z. Jusys, R.J. Behm, Langmuir 22 (2006) 10399.

[14] Y.X. Chen, M. Heinen, Z. Jusys, R.J. Behm, Angew. Chem. Int. Ed. 45 (2006) 981.

[15] M. Osawa, K.-i. Komatsu, G. Samjeské, T. Uchida, T. Ikeshoji, A. Cuesta, C. Gutiérrez, Angew. Chem. Int. Ed. 50 (2011) 1159.

[16] A. Cuesta, G. Cabello, C. Gutierrez, M. Osawa, Phys. Chem. Chem. Phys. 13 (2011) 20091.

[17] M. Arenz, V. Stamenkovic, P.N. Ross, N.M. Markovic, Surf. Sci. 573 (2004) 57.

[18] M. Arenz, V. Stamenkovic, T.J. Schmidt, K. Wandelt, P.N. Ross, N.M. Markovic, Phys. Chem. Chem. Phys. 5 (2003) 4242.

[19] A. Bandara, J. Kubota, A. Wada, K. Domen, C. Hirose, J. Phys. Chem. 100 (1996) 14962.

[20] H. Miyake, S. Ye, M. Osawa, Electrochem. Commun. 4 (2002) 973.

[21] K.-i. Ataka, T. Yotsuyanagi, M. Osawa, J. Phys. Chem. 100 (1996) 10664.

[22] G.L. Beltramo, T.E. Shubina, M.T.M. Koper, ChemPhysChem 6 (2005) 2597.

[23] O.M. Magnussen, J. Hagebock, J. Hotlos, R.J. Behm, Faraday Discuss. 94 (1992) 329.

[24] M. Kleinert, A. Cuesta, L.A. Kibler, D.M. Kolb, Surf. Sci. 430 (1999) L521.

[25] A. Cuesta, M. Kleinert, D.M. Kolb, Phys. Chem. Chem. Phys. 2 (2000) 5684. 
[26] M. Osawa, Bull. Chem. Soc. Jpn. 70 (1997) 2861.

[27] M. Osawa, in R.C. Alkire, D.M. Kolb, J. Lipkowski and P.H. Ross (Editors), Diffraction and Spectroscopic Methods in Electrochemistry, Wiley-VCH, Weinheim, 2006.

[28] G. Samjeské, K.-i. Komatsu, M. Osawa, J. Phys. Chem. C 113 (2009) 10222.

[29] L.A. Kibler, F.W. Hartl, T. Jacob, Catal. Today, this issue.

[30] A. Chmielewska, A. Wypych-Stasiewicz, A. Bald, J. Mol. Liq. 130 (2007) 42.

[31] Y.-X. Chen, M. Heinen, Z. Jusys, R.J. Behm, ChemPhysChem 8 (2007) 380.

[32] A. Cuesta, M. Escudero, B. Lanova, H. Baltruschat, Langmuir 25 (2009) 6500.

[33] M.R. Columbia, P.A. Thiel, J. Electroanal. Chem. 369 (1994) 1.

[34] A. Aramata, I. Toyoshima, M. Enyo, Electrochim. Acta 37 (1992) 1317.

[35] M.R. Columbia, A.M. Crabtree, P.A. Thiel, J. Electroanal. Chem. 345 (1993) 93.

[36] J.Y. Huang, H.G. Huang, K.Y. Lin, Q.P. Liu, Y.M. Sun, G.Q. Xu, Surf. Sci. 549 (2004) 255.

[37] R.A. Munson, J. Electrochem. Soc. 111 (1964) 372.

[38] S. Pronkin, M. Hara, T. Wandlowski, Russian Journal of Electrochemistry 42 (2006) 1177.

[39] P. Mars, J.J.F. Scholten, P. Zwietering, in W.G. Frankenburg (Editor), Advances in Catalysis, Vol. 14, Academic Press, New York, 1963, p. 35.

[40] A. López-Cudero, A. Cuesta, C. Gutiérrez, J. Electroanal. Chem. 548 (2003) 109.

[41] G. Samjeské, A. Miki, S. Ye, A. Yamakata, Y. Mukouyama, H. Okamoto, M. Osawa, J. Phys. Chem. B 109 (2005) 23509.

[42] G. Samjeské, M. Osawa, Angew. Chem. Int. Ed. 44 (2005) 5694.

[43] G. Samjeské, A. Miki, S. Ye, M. Osawa, J. Phys. Chem. B 110 (2006) 16559. 


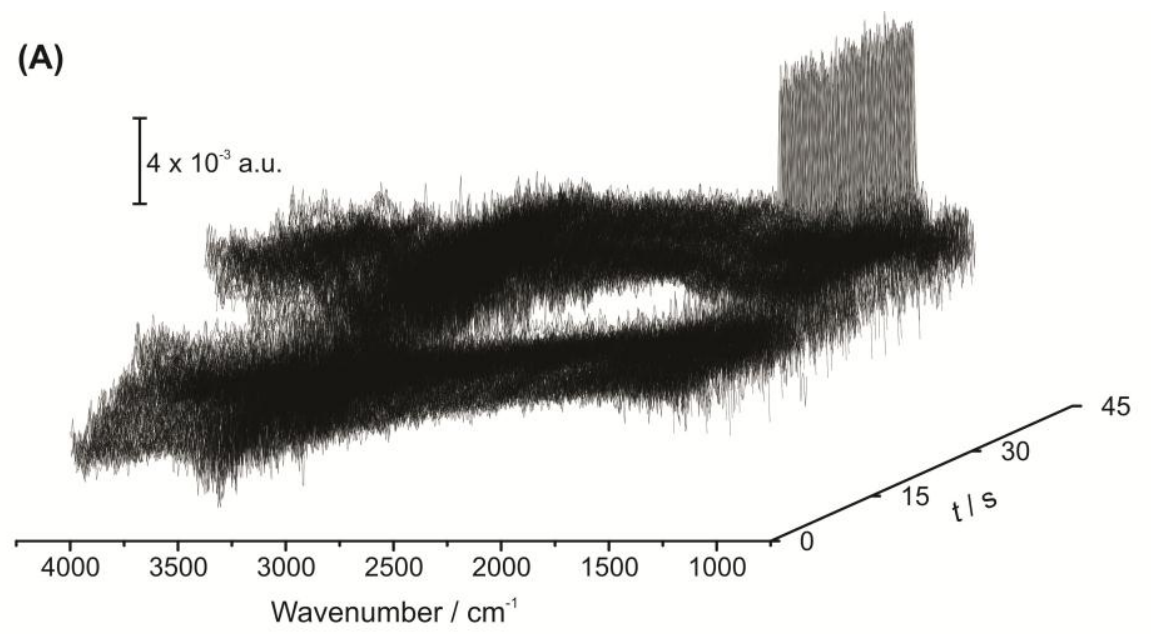

(B)

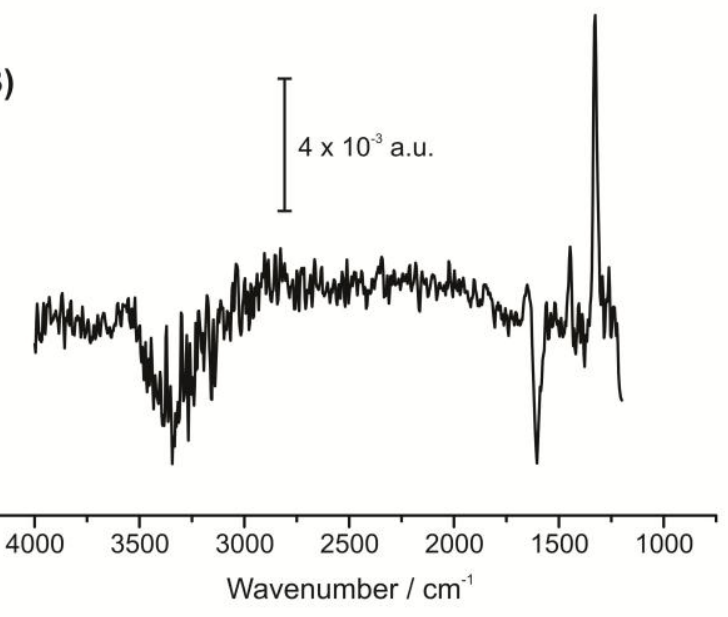

(C)

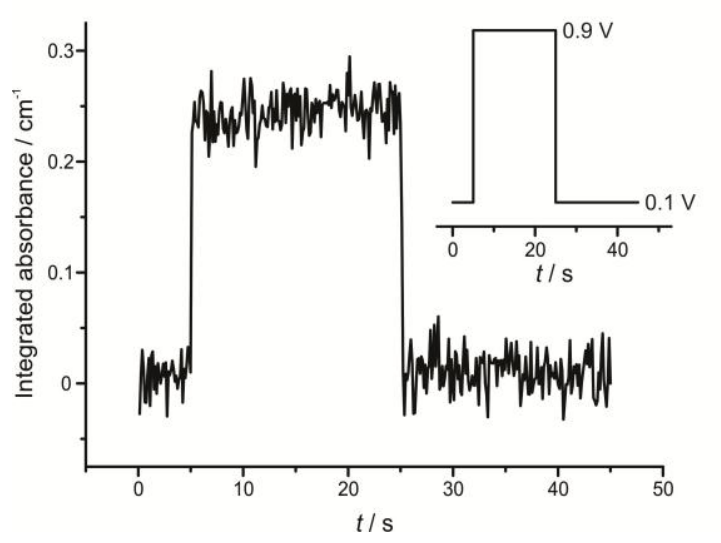

(D)

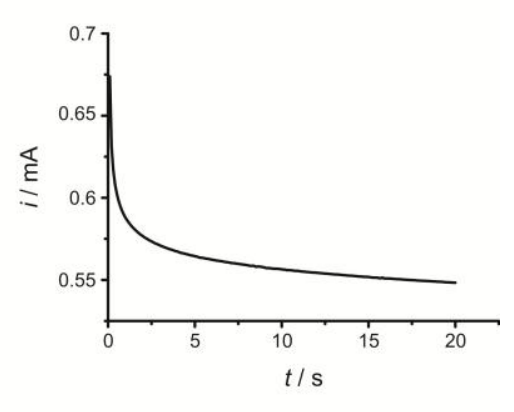

Figure 1. (A) Series of ATR-SEIRA spectra recorded with a time resolution of $140 \mathrm{~ms}$ during a potential step from 0.10 to $0.90 \mathrm{~V}$ in $0.1 \mathrm{M} \mathrm{HClO}_{4}+0.05 \mathrm{M} \mathrm{HCOOH}$. Each spectrum consists of only one interferogram and was calculated using the spectrum recorded at $0.10 \mathrm{~V}$ as reference. (B) A spectrum at $0.90 \mathrm{~V}$ extracted from the series of spectra shown in (A). (C) Integrated intensity of the band at $1330 \mathrm{~cm}^{-1}$, corresponding to the symmetric stretching of adsorbed formate, as a function of time during the potential step experiment. The inset in (C) illustrates the potential program applied. (D) Current transient recorded during the potential step from 0.10 to $0.90 \mathrm{~V}$. 
(A)

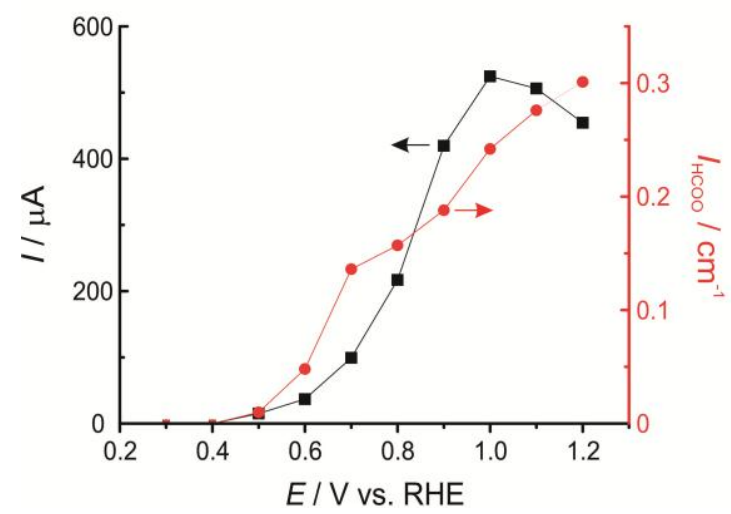

(B)

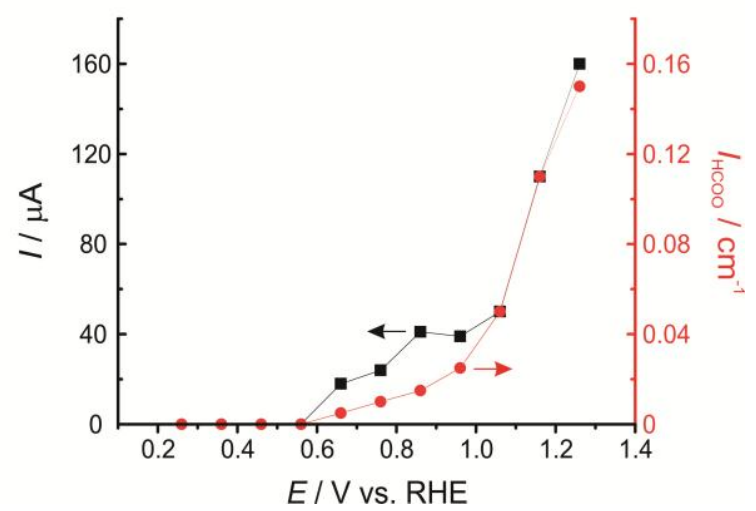

Figure 2. Potential dependence of the band intensity of adsorbed formate (red circles) and of the oxidation current (black squares) in $0.1 \mathrm{M} \mathrm{HClO}_{4}(\mathrm{~A})$ and in $0.1 \mathrm{M} \mathrm{H}_{2} \mathrm{SO}_{4}$ (B), both containing $0.01 \mathrm{M} \mathrm{HCOOH}$. The band intensity was obtained from spectra like those shown in Fig. S1 after a potential step from $0.1 \mathrm{~V}$ to the desired potential, and the oxidation current was measured $0.5 \mathrm{~s}$ after the potential step, in order to avoid contributions from double layer charging and mass transport. 

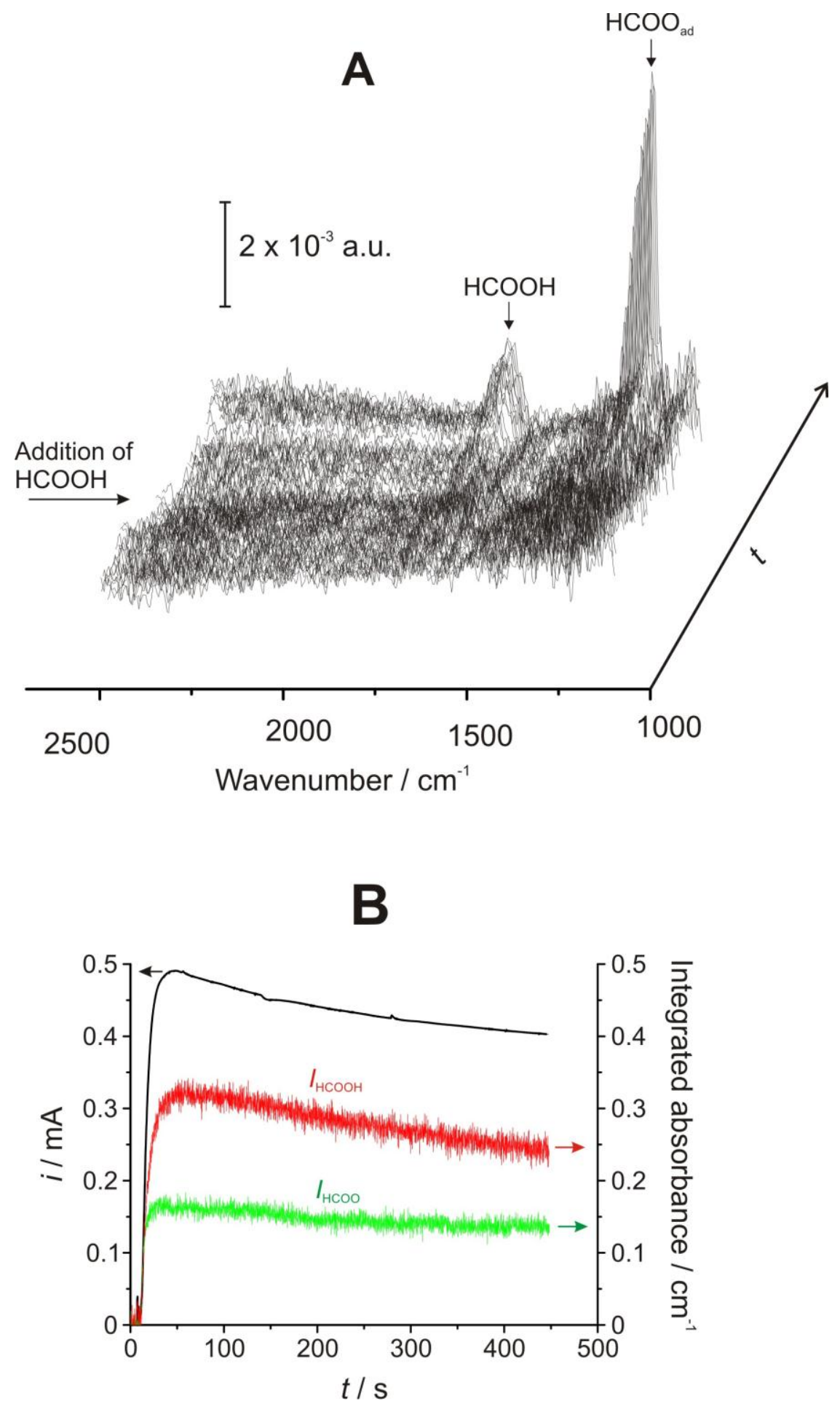

Figure 3. (A) Time-resolved ATR-SEIRA spectra of a gold electrode at $0.76 \mathrm{~V}$ in $0.1 \mathrm{M}$ $\mathrm{HClO}_{4}$ to which the amount of $\mathrm{HCOOH}$ necessary to reach a final concentration of 0.1 $\mathrm{M}$ was added at the point indicated by the arrow. A spectrum recorded at $0.76 \mathrm{~V}$ before the addition of $\mathrm{HCOOH}$ was taken as reference. (B) Evolution with time of the oxidation current $(i)$, of the integrated absorbance of the formic acid band $\left(I_{\mathrm{HCOOH}}\right)$ and of the integrated absorbance of the adsorbed formate band $\left(I_{\mathrm{HCOO}}\right)$. The decrease of the oxidation current after reaching a maximum is due to mass transport limitations, as indicated by the parallel decrease in $I_{\mathrm{HCOOH}}$. 


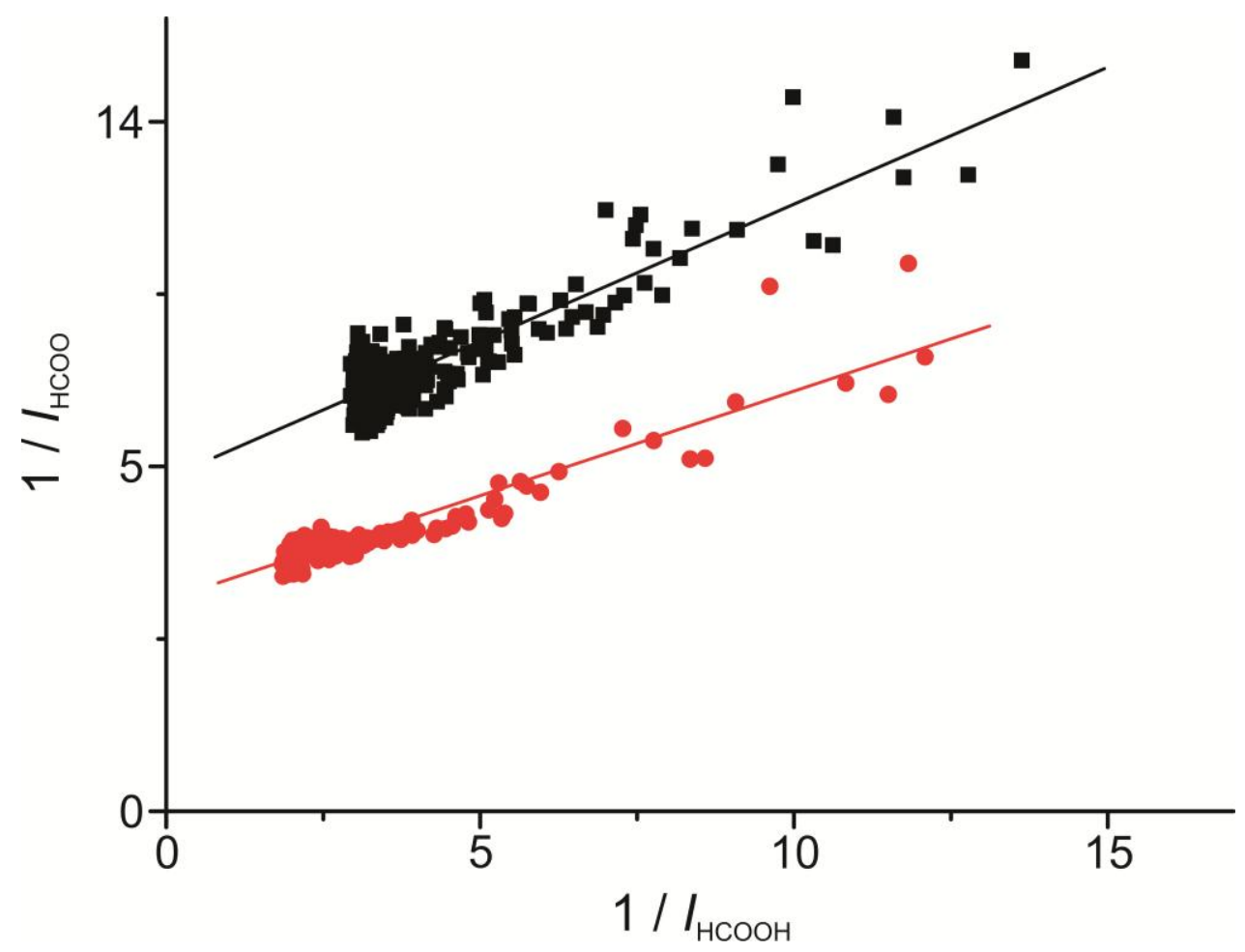

Figure 4. Langmuir plots of formate adsorption at $0.76 \mathrm{~V}$ (black squares) and $0.96 \mathrm{~V}$ (red circles). Each plot was obtained from a single experiment like those illustrated in Fig. 1 and in Fig. S4, in which the amount of $\mathrm{HCOOH}$ necessary to reach a final concentration of $0.1 \mathrm{M}$ was added to the electrolyte $\left(0.1 \mathrm{M} \mathrm{HClO}_{4}\right)$. The lines are linear fits of the experimental data.
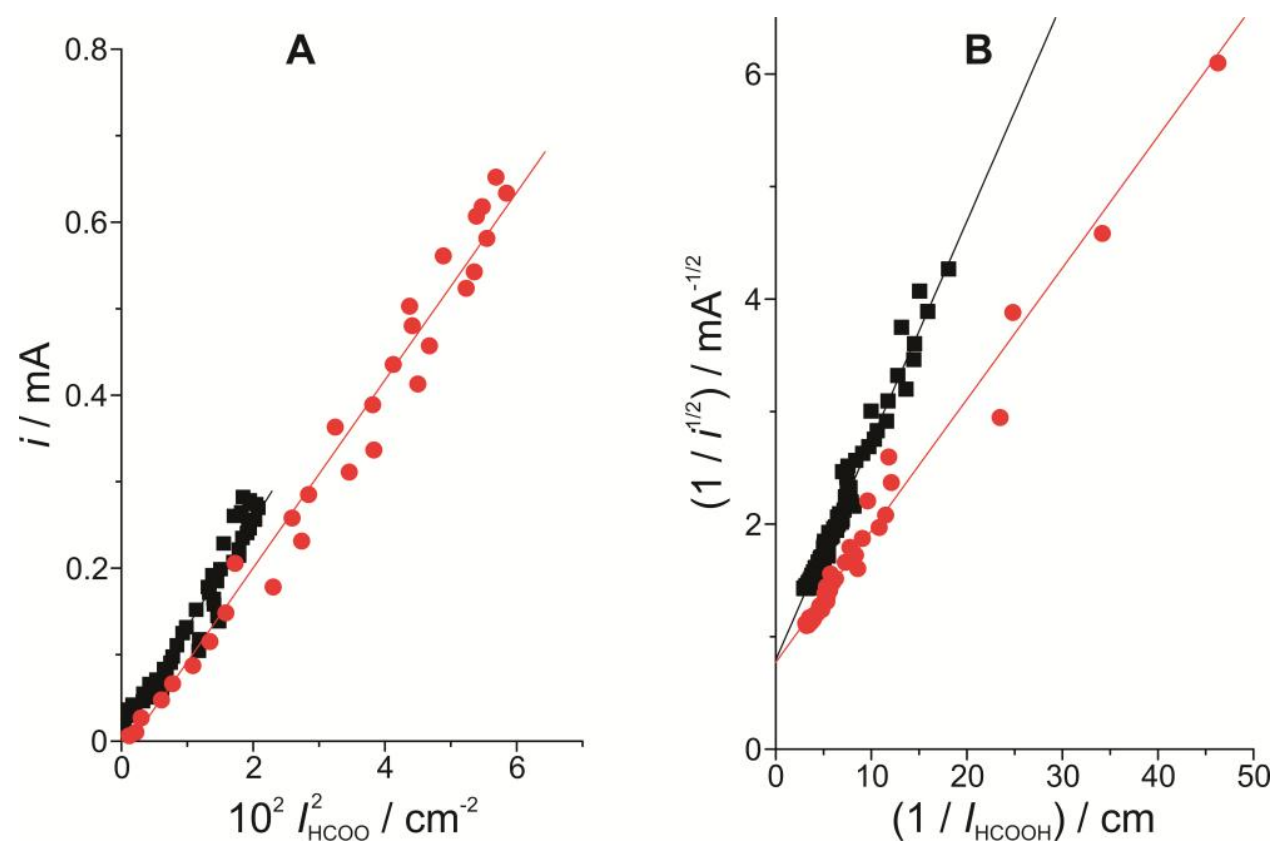

Figure 5. Plot of the oxidation current vs. the square of the integrated absorbance of the adsorbed formate band (A) and of the reciprocal of the square root of the oxidation current vs. the reciprocal of the integrated absorbance of the formic acid band (B) at $0.76 \mathrm{~V}$ (black squares) and $0.96 \mathrm{~V}$ (red circles). The lines are linear fits of the experimental data to Eq. 2 (A) and to Eq. 5 (B). 


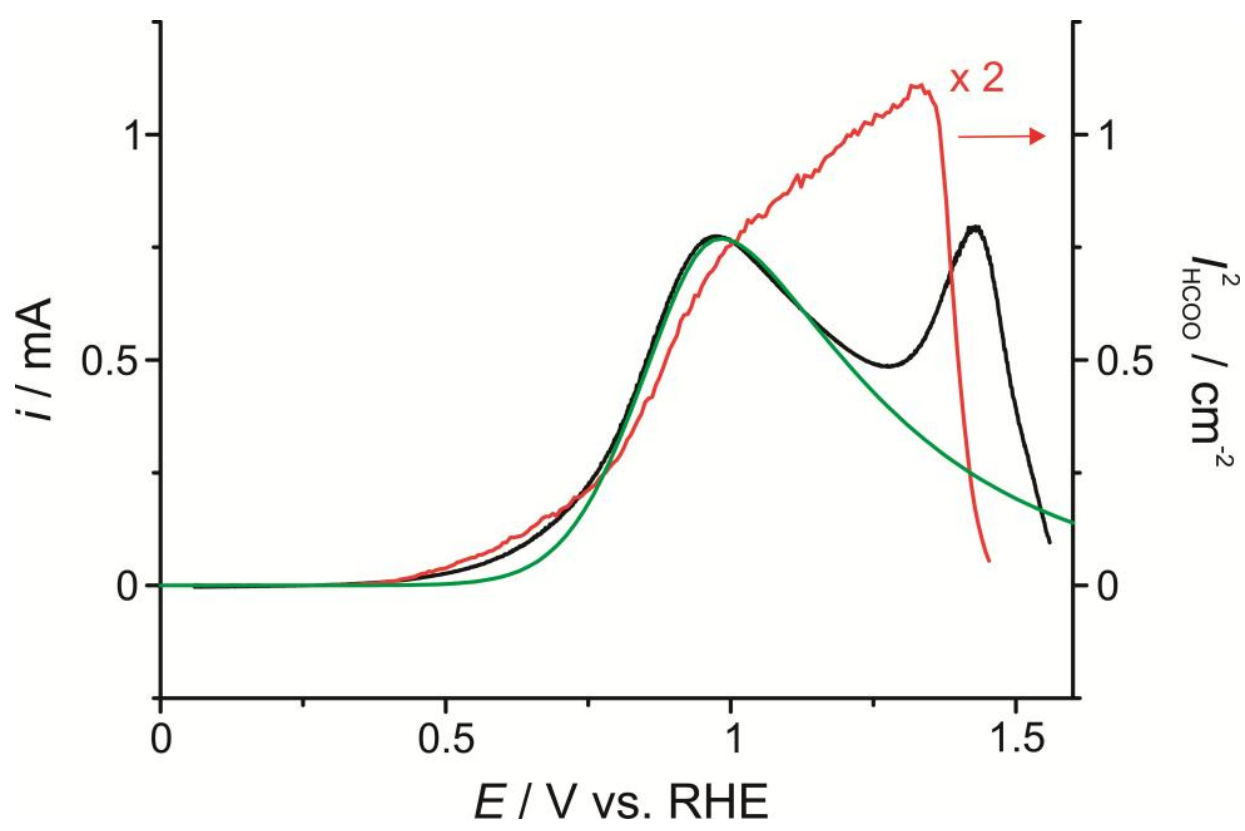

Figure 6. Cyclic voltammogram at $1 \mathrm{mV} \mathrm{s}^{-1}$ (black line) in $0.1 \mathrm{M} \mathrm{HClO}_{4}+0.1 \mathrm{M}$ $\mathrm{HCOOH}$ and plot of the square of the integrated intensity of the formate band $\left(I^{2}{ }_{\mathrm{HCOO}}\right)$ (red line) vs. the electrode potential obtained from simultaneously recorded infrared spectra. At $E<1.0 \mathrm{~V}$ the oxidation current and $I^{2}{ }_{\text {HCOO }}$ run approximately in parallel, as expected from Eq. 2, but they diverge above $1.0 \mathrm{~V}$. The divergence is attributed to $\mathrm{OH}$ adsorption at $E>1.0 \mathrm{~V}$, that will decrease the probability that two adsorbed formates will occupy two adjacent sites. The green curve was obtained by fitting the experimental data to Eq. 7. 